\title{
Prediction of Surface Roughness in Drilling of Polymers Using a Geometrical Model and Artificial Neural Networks
}

\author{
NICUSOR BAROIU ${ }^{1}$, GEORGIANA-ALEXANDRA COSTIN ${ }^{1}$, VIRGIL GABRIEL TEODOR ${ }^{1}$, \\ DUMITRU NEDELCU ${ }^{2}$, VALENTIN TABACARU ${ }^{* *}$ \\ 1 "Dunarea de Jos" University of Galati, Faculty of Engineering, Department of Manufacturing Engineering, 111 Domneasca \\ Str., 800201, Galati, Romania \\ 2 "Gheorghe Asachi" Technical University of Iasi, Faculty of Machine Manufacturing and Industrial Management, 43 Prof. \\ Dr. Doc. Dimitrie Mangeron, 700050, Iasi, Romania
}

Abstract: Polymeric materials are synthetic macromolecular products, of which, by mechanical or thermal processing, objects of various shapes can be obtained, with wide uses in industry and commerce. This paper deals with the roughness of surfaces obtained during drilling of three polymeric materials: polyamide - PA6, polyacetal - POM-C and high density polyamide - HDPE 1000. In the experimental research was used a EMCO MILL 55 milling machine numerical controlled and HS steel helical drills with two straight cutting edges with the diameter of $\emptyset 8 \mathrm{~mm}$ and $\emptyset 10 \mathrm{~mm}$, respectively. Experimental determinations consisted in drilling of the polymeric materials by modifying some parameters of the cutting regime, and determining the roughness of the surface of the holes machined, using the Mitutoyo Surftest SJ-210 rough meter. The purpose of the paper is to predict the roughness of the machined surfaces as one of the important surface quality indicators by using a geometrical model and an artificial neural network (ANN) methodology.

Keywords: roughness, helical drill, polymeric materials, artificial neural network (ANN)

\section{Introduction}

In general, the machining of materials, namely of polymeric materials, involves the participation of several different elements such as: the cutting tool, the cutting regime with its parameters (the depth of cut, the feed, the cutting speed); the material to be processed; cutting conditions (dry, wet, cold or hot etc.) and the machine tool with specific kinematics [1-6].

Although among metal machining methods, drilling, as a full hole processing, is a highly used process - about $36 \%$ of the total metal cutting, consuming almost $42 \%$ of the time allocated to processing in the machining processes [7], an increased importance is given to the polymeric materials, as alternative to the conventional metallic materials. The advantage of polymeric materials regarding the rigid metallic materials is given by their smaller density which lead to lighter and less complex structures. In the automotive industry, holes processing is considered a complex machining process which is widely applied, accounting for about $50 \%$ of the total mechanical working processes, the proportion in the aeronautical industry being even higher [8].

In spite of the fact that HSS drills are used in a percentage of only $11 \%$ of the total drilling, but also because they are commonly used on conventional machines, the still considerable share of HSS drills, especially of those with diameters between $\emptyset 6 \div \varnothing 16 \mathrm{~mm}$, is significant and not to be neglected, which imposes new approaches on increasing their cutting capacity and analyzing the state of the processed surfaces [9-14].

The existence of micro-irregularities on the surfaces of the parts leads, in more severe functional conditions, to a series of disadvantages: it reduces the effective contact surface of the comprising piece - comprised piece couple, it worsens the operating and friction conditions of the parts, it builds up stress concentrators, which decrease the resistance to fatigue, changes the actual dimensions of the parts and implicitly the character of the adjustments.

\footnotetext{
*email: Valentin.Tabacaru@ugal.ro
} 
In these conditions, many authors have developed predictive models for roughness in order to estimate the values of some roughness parameters of the cylindrical holes processed in the drilling process [15-24].

A. Uysal [19] investigated the effects of geometry, feed rate and cutting speed on the temperature during the drilling of a non-reinforced or carbon fiber reinforced polyamide, by Taguchi and ANOVA statistical methods. Depending on the parameters of the cutting parameters (feed of 0.1 , and respectively $0.3 \mathrm{~mm} / \mathrm{rot}$, the cutting speed of 40, and respectively $120 \mathrm{~m} / \mathrm{min}$ ), temperature models were established by multivariable linear regression analysis. For the models obtained in the processing of non-reinforced polyamide and respectively carbon fiber reinforced polyamide errors of 1.874 and $2.067 \%$ were estimated.

C. Tsao [20] evaluated surface roughness when drilling a composite material using Taguchi methods and neural networks, showing that the most important factors affecting surface roughness are feed rate and the cutting speed.

S. Aykut [21] predicted the surface roughness of a polyamide (castamide) material, after the CNC milling process, through an artificial neural network. A $14 \mathrm{~mm}$ diameter milling cutter was used, with the following experimental cutting parameters: cutting speed: 100,120 and $140 \mathrm{~m} / \mathrm{min}$, feed rate: 75 , 100 and $125 \mathrm{~mm} / \mathrm{min}$. The data were used to train and test a dynamic ANN model. The developed model had a correlation rate of $83.6 \%$ and a minimum error rate of 0.02 .

C. Sanjay [22] estimated the values of surface roughness, using comparatively methods of mathematical analysis and of neural networks, in a drilling process with three cutting speeds (9.047, 12.31 and $17.9 \mathrm{~m} / \mathrm{min})$ and three feeds $(0.095,0.19$ and $0.285 \mathrm{~mm} / \mathrm{rot})$, with a drill with a diameter of 8 $\mathrm{mm}$, the number of holes ranging from 1 to 40, for a $30 \mathrm{~mm}$ depth of hole. The results, both the predicted and the experimental ones, showed that an increase of the feed rate, respectively of the cutting speed, leads to the worsening of the surface quality.

F. Susac [23] performed an analysis of variance (ANOVA) based on the mechanics and dynamics of the drilling process in order to forecast the quality of the surfaces processed during the planning stage of the drilling process for three types of polymeric materials. In the cutting process, spindle speeds between $500 \div 1250 \mathrm{rot} / \mathrm{min}$. and feed rate of 25,50 and $75 \mathrm{~mm} / \mathrm{min}$ were taken into consideration. It was possible to measure roughness, cylindricity and circularity and to compare them with the results of the dynamic, theoretical model.

In order to establish the role that the working parameters have in the processing by drilling of three polymeric materials - polyamide (PA6), polyacetal (POM-C) and high density polyethylene (HDPE 1000), roughness measurements were made when drilling with standard drills with two rectilinear cutting edges.

\section{Materials and methods}

\subsection{Geometric model of surface roughness obtained when drilling with the drill with straight cutting edge}

It is accepted the approximation that the geometric roughness (generation roughness) is obtained by the main cutting edge of the drill and by the helical line of the secondary cutting edge, for two successive positions of the drill, in its rotation along its own axis, with a distance equal to the feed per tooth. The main cutting edge is rectilinear (in the axial plane of the hole, as the first constructive approximation of the twist drill), while the secondary cutting edge is a cylindrical helix, Figure 1.

Moreover, it is considered that approximation is acceptable, given the size of the feed per tooth $\left(s_{d}\right)$, that the secondary cutting edge can be replaced by the tangent to it. Thus, for the drills with two cutting edges, $s_{d}=F / 2$, where $F$ is the size of the feed rate [mm/rot]. 


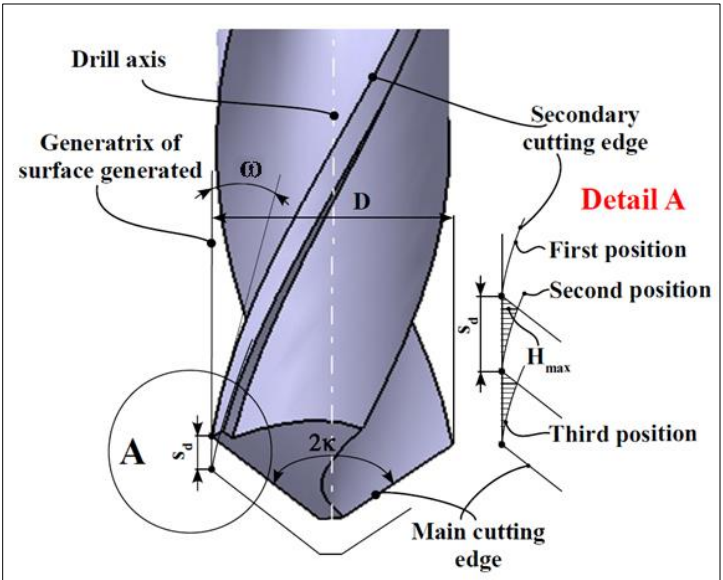

Figure 1. The drilling process - drill with straight cutting edge [24]

Figure 2 shows the position (the mark) of the main cutting edge $\overline{A B}$ of the tooth of drill and, also, the position of the secondary cutting edge of the second generating cutting edge $\left(A^{\prime} C^{\prime}\right)$.

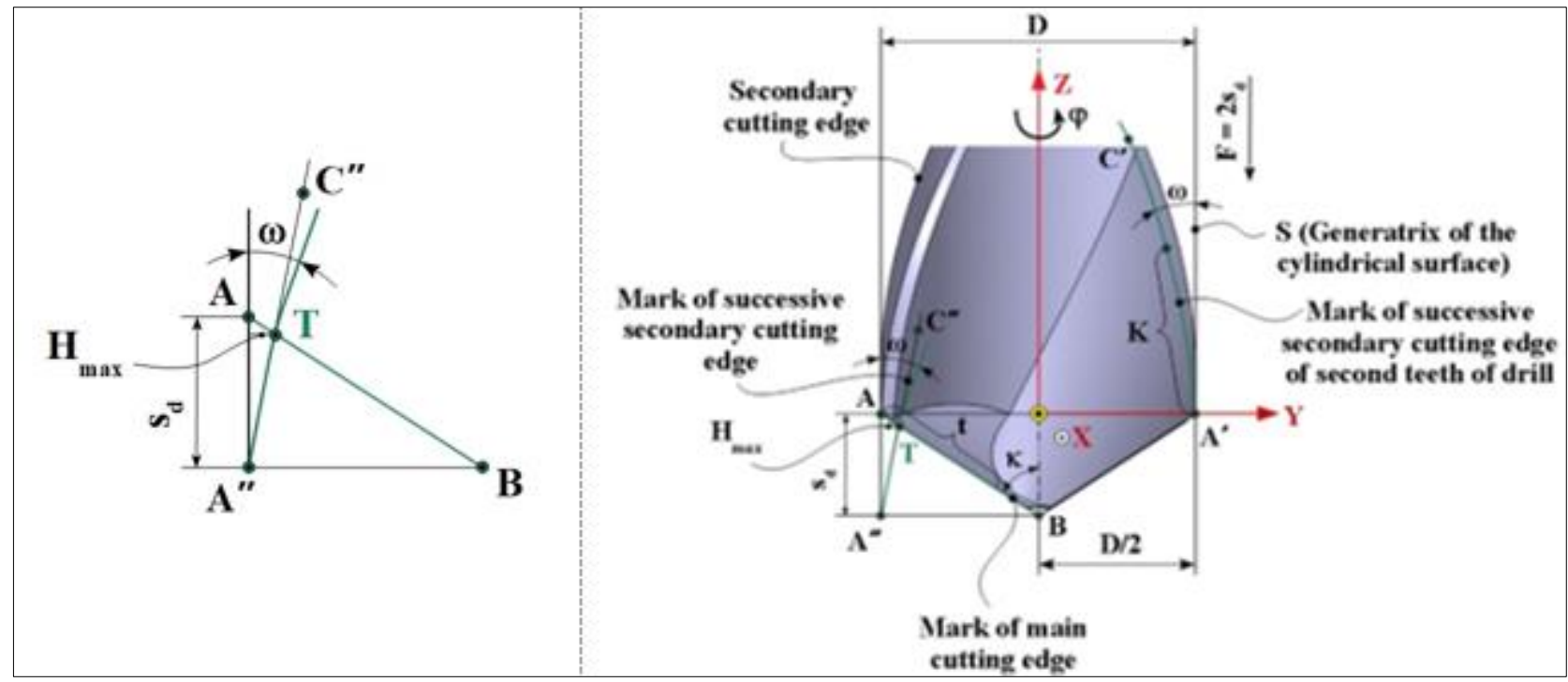

Figure 2. Mark of the main and secondary cutting edge at a drill with straight cutting edges

It is considered that the marks of the main and secondary cutting edges are in the plane of the anterior main cutting edge.

- $A^{\prime \prime} B^{\prime \prime}$ position - represents the mark of the hole on surface $S$ after turning the drill $\varphi$ around its own axis $(\varphi=\pi)$ so that the two marks are successively represented in the same plane (left).

- The mark of the main cutting edge on surface $S$ (generatrix of the machined hole),

$$
\overline{A B} \mid \begin{aligned}
& X=0 \\
& Y=-\frac{D}{2}+t \cdot \sin \kappa \\
& Z=-t \cdot \cos \kappa
\end{aligned}
$$

where:

$t$ - variable parameter along the straight line $A C$ (mark on $S$ );

$D$ - drill diameter. 
- The mark of the successive secondary cutting edge of the successive second tooth of the drill on the generatrix $S$ of the hole generated:

$$
A^{\prime} C^{\prime} \mid \begin{aligned}
& X=0 \\
& Y=\frac{D}{2}-K \cdot \sin \omega \\
& Z=K \cdot \cos \omega
\end{aligned}
$$

where:

$K$ - variable parameter along $A^{\prime} C^{\prime}$.

In both representations, $\overline{A B}$ and $A^{\prime} C^{\prime}$, it is considered that the marks are in the same plane $Z Y(X$ $=0$ ), that is, they are accepted with the core of the drill $d_{0}=0$.

- By the forward helical motion of the segment $A^{\prime} C^{\prime}$, at the rotation with the angle $\varphi=\pi$, around the $\mathrm{Z}$ axis (the drill axis), the position of the mark of secondary cutting edge in the $A B$ plane is determined. Thus, in the XYZ system,

$$
\left(\begin{array}{c}
X \\
Y \\
Z
\end{array}\right)=\omega_{3}^{T}(\varphi) \cdot\left(\begin{array}{c}
0 \\
D / 2-K \cdot \sin \omega \\
K \cdot \cos \omega
\end{array}\right)-\left(\begin{array}{c}
0 \\
0 \\
s_{d}
\end{array}\right)
$$

which, for $\varphi=\pi$ (half rotation), has the form:

$$
\left(\begin{array}{l}
X \\
Y \\
Z
\end{array}\right)=\left(\begin{array}{ccc}
\cos \varphi & -\sin \varphi & 0 \\
\sin \varphi & \cos \varphi & 0 \\
0 & 0 & 1
\end{array}\right) \cdot\left(\begin{array}{c}
0 \\
D / 2-K \cdot \sin \omega \\
K \cdot \cos \omega
\end{array}\right)-\left(\begin{array}{c}
0 \\
0 \\
s_{d}
\end{array}\right)
$$

If $\varphi=\pi$ (half rotation), the following form is reached:

$$
A^{\prime \prime} C^{\prime \prime} \mid\left(\begin{array}{l}
X \\
Y \\
Z
\end{array}\right)=\left(\begin{array}{ccc}
-1 & 0 & 0 \\
0 & -1 & 0 \\
0 & 0 & 1
\end{array}\right) \cdot\left(\begin{array}{c}
0 \\
D / 2-K \cdot \sin \omega \\
K \cdot \cos \omega
\end{array}\right)-\left(\begin{array}{c}
0 \\
0 \\
s_{d}
\end{array}\right),
$$

respectively,

$$
A^{\prime \prime} C^{\prime \prime} \mid \begin{aligned}
& X=0 \\
& Y=-(D / 2-K \cdot \sin \omega) \\
& Z=K \cdot \cos \omega-s_{d}
\end{aligned}
$$

representing "the mark" of the successive secondary cutting edge in the axial plane of the drill, $A B$.

The point of intersection of $\overline{A B}$ and $A^{\prime} C^{\prime}$ marks is determined from the equations (1) and (6):

$$
\left\{\begin{array}{l}
-\frac{D}{2}+t \cdot \sin \kappa=-\left(\frac{D}{2}-K \cdot \sin \omega\right), \\
-t \cdot \cos \kappa=K \cdot \cos \omega-s_{d}
\end{array}\right.
$$


which represent the coordinates of point $T$, Figure 3.

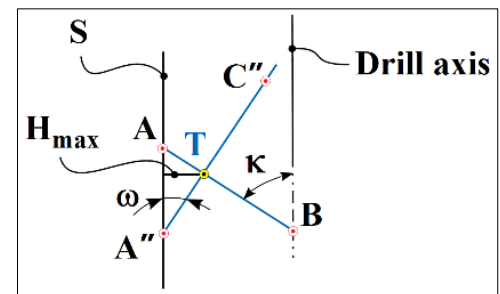

Figure 3. The geometric model of roughness, $H_{\max }$

The system of equations (7) allows determining the sizes of the parameters $t$ and $K$, corresponding to the maximum height of the model of roughness. Thus, the following conditions result from (7):

$$
\left\{\begin{array}{l}
t \cdot \sin \kappa=K \cdot \sin \omega \\
s_{d}=t \cdot \cos \kappa+K \cdot \cos \omega
\end{array}\right.
$$

Note that $H_{\max }=t \cdot \sin \kappa$, where $H_{\max }$ is the maximum size of the geometric model of roughness, Figure 1 and Figure 3 and, similarly, $H_{\max }=t \cdot \sin \omega$. The size of the angle $\omega$ is determined, Figure 4:

$$
\operatorname{tg} \omega=\frac{\pi \cdot D}{2 \pi \cdot p}
$$

where:

$p$ - helical parameter of helix representing the secondary cutting edge of the drill.

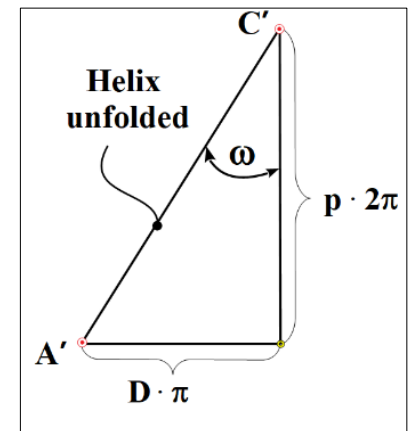

Figure 4. Helix unfolded

It is accepted that the helix $A^{\prime} C^{\prime}$ is replaced with the line $\overline{A^{\prime} C^{\prime}}$. From system processing $(8)$ the following form is reached:

with $\operatorname{tg} \omega=D / 2 p$, see (9).

$$
H_{\max }=s_{d} \cdot \frac{\operatorname{tg} \kappa \cdot \operatorname{tg} \omega}{\operatorname{tg} \omega+\operatorname{tg} \kappa}
$$

Equation (10) represents the known form of the approximation of the geometric roughness size, which shows that:

- the size of the feed rate leads to increased geometric roughness;

- geometric roughness decreases with the increase in the helical pitch of the drill's flute helix; angle $\omega$ is reduced; 
- the decrease of point angle leads to a reduction of geometric roughness.

The geometric (mathematical) model is a general one and has the goal to show only the influence of geometrical parameters of cutting tool and parameters of cutting regime to the surface's quality, without considering the processes of plastic deformation for the detached material. These processes can substantially influence the actual roughness obtained by machining. Between the geometrical roughness and the actual one cannot be obtained a relationship of proportionality, generalized for various materials types. The influence of geometrical parameters can be only qualitative.

In this context, it is proposed to change the geometry of the helical drills, by changing the point angle, $\kappa$, in the sense of reducing it. In Figure 5, there are 4 variants of helical drill with straight cutting edge, with values of angle $\kappa=60^{\circ}, \kappa=45^{\circ}, \kappa=30^{\circ}$ and $\kappa=22^{\circ}$, and drill diameter size $D=10 \mathrm{~mm}$.

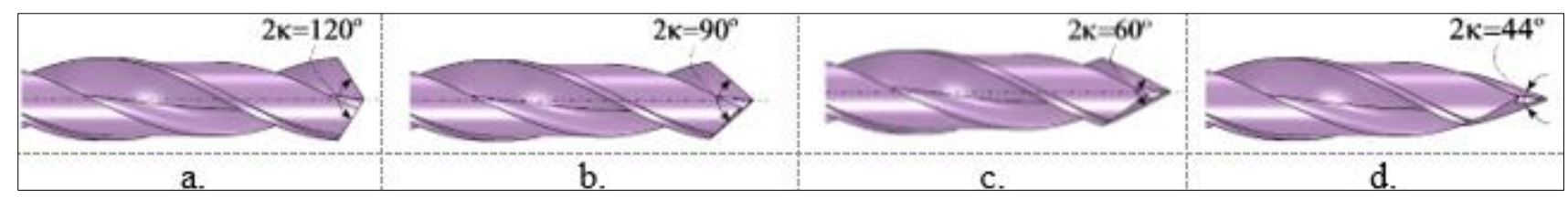

Figure 5. Helical drills with straight cutting edge with different values of the point angle, for the diameter of $\varnothing 10 \mathrm{~mm}: \kappa=60^{\circ}(\mathrm{a}), \kappa=45^{\circ}(\mathrm{b}), \kappa=30^{\circ}(\mathrm{c})$ and $\kappa=22^{\circ}(\mathrm{d})$

Under the conditions of using drills with diameter $\mathrm{D}=10 \mathrm{~mm}$, respectively $\mathrm{D}=8 \mathrm{~mm}$, based on the relations (9) and (10), values of the approximation of geometric roughness size, $H_{\max }$, can be obtained for different sizes of the feed rate, respectively of the point angle, Figure 6.

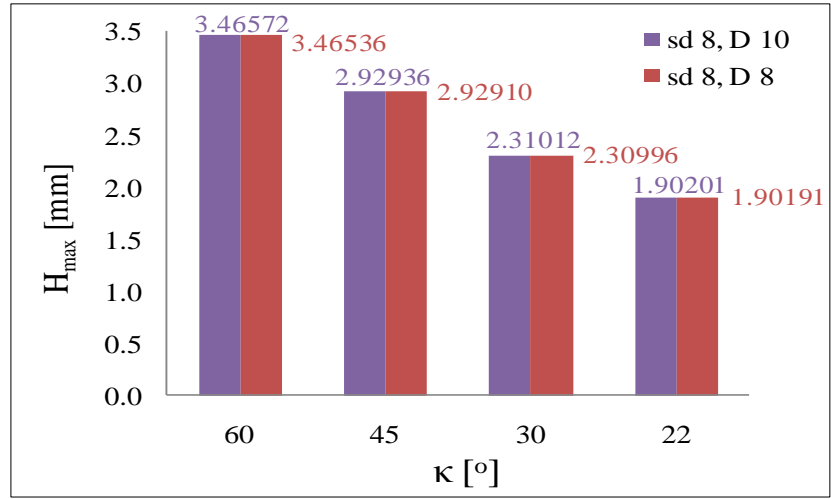

a.

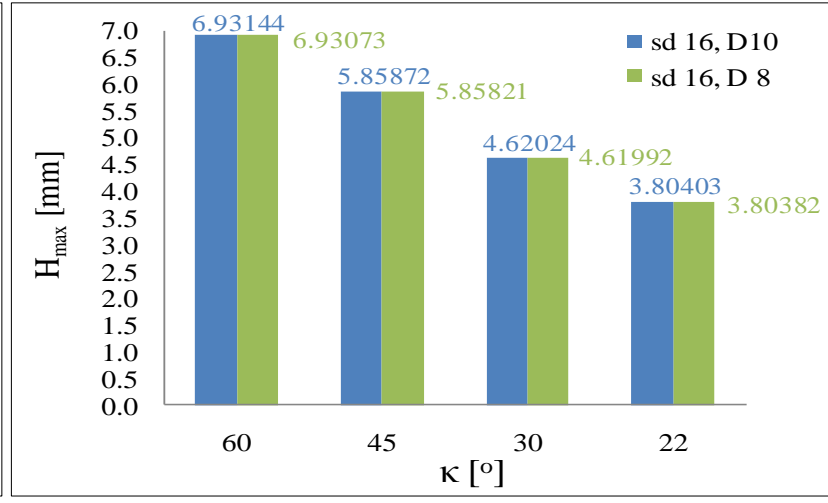

b.

Figure 6. Variation of maximum geometric roughness $H_{\max }$ :

$D_{l}=10 \mathrm{~mm} ; D_{2}=8 \mathrm{~mm} ; s_{d}=16 \mathrm{~mm}(\mathrm{a}) ; D_{l}=10 \mathrm{~mm} ; D_{2}=8 \mathrm{~mm} ; s_{d}=8 \mathrm{~mm}$ (b)

For the two diameters of the helical drills it can be noticed that the maximum height of geometric roughness $H_{\max }$, varies with the decrease of the point angle, $\kappa$, and respectively, of the feed per tooth, $s_{d}$.

The geometric roughness (generation roughness) is, in all cases, much different from the measurable surface roughness, but it may provide indications regarding the influence of the different geometric parameters of the tool on the cross-sectional roughness of the generated surface: the feed rate, geometric parameters (point angle), the actual shape of the cutting edge etc.

\subsection{Materials}

In the experimental research, a set of two high-speed steel helical drills HS18-0-1 (SR EN ISO 4957) with diameters of $8 \mathrm{~mm}$ and $10 \mathrm{~mm}$ was used. To perform the tests, 24 plates with the dimensions of 210x62x32 mm were used, 8 of PA6 (polyamide - ertalon $6 \mathrm{SA}$ ), 8 of POM-C (polyacetal - ertacetal C) and 8 of HDPE 1000, having the mechanical properties defined in Tables 1, 2 and 3 respectively. 
Table 1. Mechanical characteristics of PA6 [26]

\begin{tabular}{|c|c|c|c|c|}
\hline $\begin{array}{c}\text { Tensile strain at yield, } \\
{[\%]}\end{array}$ & $\begin{array}{c}\text { Tensile strain at } \\
\text { break, [\%] }\end{array}$ & $\begin{array}{c}\text { Tensile strength, } \\
{[\mathrm{MPa}]}\end{array}$ & $\begin{array}{c}\text { Rockwell M- } \\
\text { hardness }\end{array}$ & $\begin{array}{c}\text { Tensile modulus of } \\
\text { elasticity, }[\mathrm{MPa}]\end{array}$ \\
\hline 4 & 50 & 84 & 88 & 3300 \\
\hline
\end{tabular}

Table 2. Mechanical characteristics of POM C [26]

\begin{tabular}{|c|c|c|c|c|}
\hline $\begin{array}{c}\text { Tensile strain at } \\
\text { yield, [\%] }\end{array}$ & $\begin{array}{c}\text { Tensile strain at } \\
\text { break, [\%] }\end{array}$ & $\begin{array}{c}\text { Tensile strength, } \\
{[\mathrm{MPa}]}\end{array}$ & $\begin{array}{c}\text { Rockwell M- } \\
\text { hardness }\end{array}$ & $\begin{array}{c}\text { Tensile modulus of } \\
\text { elasticity, [MPa] }\end{array}$ \\
\hline 12 & 50 & 66 & 83 & 3100 \\
\hline
\end{tabular}

Table 3. Mechanical characteristics of HDPE 1000 [26]

\begin{tabular}{|c|c|c|c|c|}
\hline $\begin{array}{c}\text { Tensile strain at } \\
\text { yield, [\%] }\end{array}$ & $\begin{array}{c}\text { Tensile strain at } \\
\text { break, [\%] }\end{array}$ & $\begin{array}{c}\text { Tensile strength, } \\
{[\mathrm{MPa}]}\end{array}$ & $\begin{array}{c}\text { Rockwell M- } \\
\text { hardness }\end{array}$ & $\begin{array}{c}\text { Tensile modulus of } \\
\text { elasticity, [MPa] }\end{array}$ \\
\hline 15 & $>50$ & 21 & 61 & 800 \\
\hline
\end{tabular}

\subsection{Equipment}

The processing of polymeric materials was performed using a computer numerical control machine, EMCO MILL 55 CNC, for which four coordinate systems are defined: machine system (absolute); the reference system, within which the displacement measurement system is synchronized; the main shaft system, in which the tool length is measured; the system of the piece. To fix the parts, rulers with seating surfaces larger than $60 \times 60 \mathrm{~mm}$, are used directly on the working table of the machine, Figure 7.

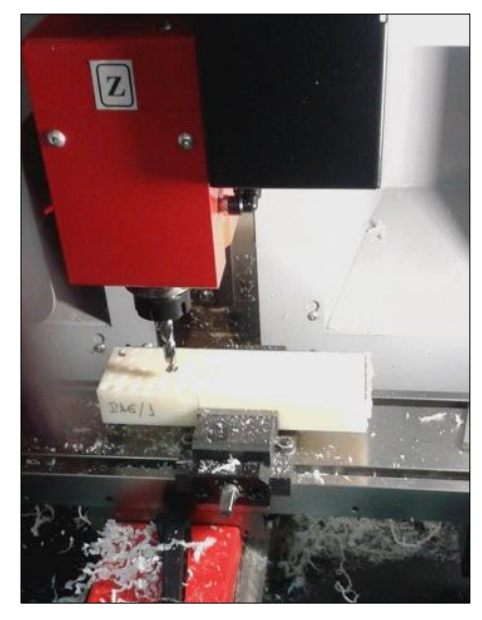

Figure 7. EMCO MILL 55 CNC

milling and drilling machine

Roughness was measured using a roughness tester, Mitutoyo Surftest SJ-210, its probe having the possibility to move on a maximum length of $5 \mathrm{~mm}$, Figure 8 . The measurements were taken with the software Surftest SJ Communication Tool which allowed quantifying several basic parameters of the surface of the plate to be assessed.

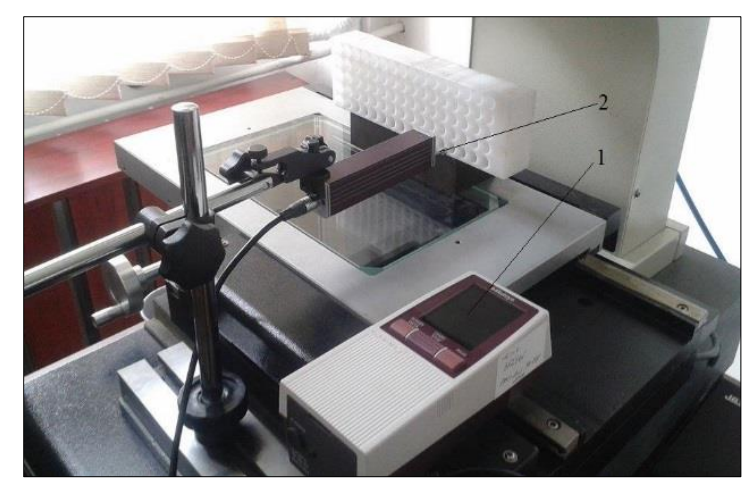

Figure 8. Measurement of roughness:

(1) Mitutoyo Surftest profilometer; (2)

Position of the probe

The working parameters for the plates to drilling 
were established according to Table 4 .

Table 4. Working parameters: $D$ - drill diameter; $v$ - the cutting speed; $n$ - rotational speed;

\begin{tabular}{|c|c|c|c|c|c|}
\hline \multicolumn{7}{|c|}{$v_{f}$ - feed velocity; $F-$ feed rate } \\
\hline $\begin{array}{c}\text { Nr. } \\
\text { crt. }\end{array}$ & $\begin{array}{c}D \\
{[\mathrm{~mm}]}\end{array}$ & $\begin{array}{c}v \\
{[\mathrm{~m} / \mathrm{min}]}\end{array}$ & $\begin{array}{c}n \\
{[\mathrm{rpm}]}\end{array}$ & $\begin{array}{c}v_{f} \\
{[\mathrm{~mm} / \mathrm{min}]}\end{array}$ & $\begin{array}{c}F \\
{[\mathrm{~mm} / \mathrm{rev}]}\end{array}$ \\
\hline 1 & 10 & 16 & 509 & 30 & 0.06 \\
\hline 2 & 10 & 32 & 1018 & 30 & 0.03 \\
\hline 3 & 10 & 16 & 509 & 75 & 0.15 \\
\hline 4 & 10 & 32 & 1018 & 75 & 0.07 \\
\hline 5 & 8 & 16 & 636 & 30 & 0.05 \\
\hline 6 & 8 & 32 & 1273 & 30 & 0.02 \\
\hline 7 & 8 & 16 & 636 & 75 & 0.12 \\
\hline 8 & 8 & 32 & 1273 & 75 & 0.06 \\
\hline
\end{tabular}

The tests were performed under the same cutting conditions, without modifying the chisel edge of drill bit. The plate of $210 \times 62 \times 32 \mathrm{~mm}$ was attached to the machine sheet by means of clamps.

\subsection{Research methodology}

It was agreed to establish a working plan for drilling the plates with diameter $\emptyset 8 \mathrm{~mm}$, respectively $\varnothing 10 \mathrm{~mm}$, generically represented in Figure 9.

In this case, the origin of the first hole was considered to be at a distance of $9 \mathrm{~mm}$ from the corner of the plate, in the direction of the $+X$ and $+Y$ axes of the CNC machine. Prior to the actual processing, a center drill bit with a diameter of $\emptyset 8 \mathrm{~mm}$ was used to perform a pre-drilling.

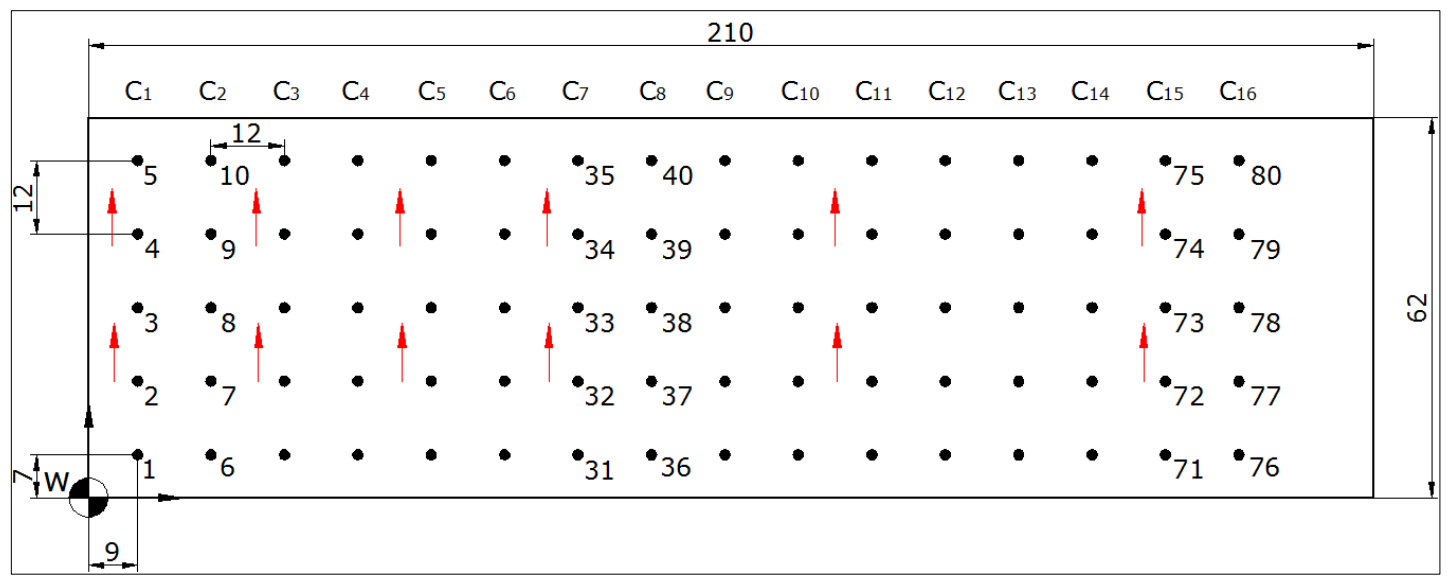

Figure 9. Choosing the origin of the CNC machine: drill $\varnothing 8 \mathrm{~mm}$; drill $\varnothing 10 \mathrm{~mm}$

After centering the 80 holes, modifications were made to the $\mathrm{CNC}$ code, proceeding to a new processing (from the center drill bit to the drill bit). The drilling depth, when drilling the materials with the two types of drills, was $15 \mathrm{~mm}$. These preliminary data, together with the specifications of the cutting parameters, were part of the G code, transmitted to the CNC machine. Taking into consideration that the chips resulting from the processing of the holes do not automatically detach from the tool, the processing will be done for each column separately, the changes made to the program of the CNC machine being related only to the change of parameters $X$. The roughness parameter evaluated using Mitutoyo Surftest SJ-210 roughness tester was $R_{a}$ [25].

The calibration of the device was performed on a roughness standard sample $R_{a}=2.97 \mu \mathrm{m}$. For each processed hole, profile measurements were made in 4 areas, on an inspection length $\left(l_{n}\right)$ of $4 \mathrm{~mm}$, on the 
same generatrix, from the bottom of the hole to the inlet area of the drill.

\section{Results and discussions}

Following the drilling of the plates of $210 \times 62 \times 32 \mathrm{~mm}$ of PA6, POM-C and HDPE 1000, using helical drills as cutting tools, varying the cutting parameters according to Table 4, after processing the data recorded in the Surftest SJ Communication Tool, the measures obtained were grouped in a table and in graphical format; in this respect, Table 5 and Figures $10 \div 13$ are illustrative.

Table 5. Values of the arithmetic mean of roughness $R_{a}$

\begin{tabular}{|c|c|c|c|c|c|c|c|c|c|c|c|c|c|c|}
\hline & Mater. & $\begin{array}{c}D \\
{[\mathrm{~mm}]}\end{array}$ & $\begin{array}{c}v \\
{[\mathrm{~m} / \mathrm{min}]}\end{array}$ & $\begin{array}{c}F \\
{[\mathrm{~mm} / \mathrm{rev}]}\end{array}$ & $\begin{array}{c}R_{a} \\
{[\mu \mathrm{m}]}\end{array}$ & $\begin{array}{c}\text { Standard } \\
\text { deviation }\end{array}$ & & Mater. & $\begin{array}{c}D \\
{[\mathrm{~mm}]}\end{array}$ & $\begin{array}{c}v \\
{[\mathrm{~m} / \mathrm{min}]}\end{array}$ & $\begin{array}{c}F \\
{[\mathrm{~mm} / \mathrm{rev}]}\end{array}$ & $\begin{array}{c}R_{a} \\
{[\mu \mathrm{m}]}\end{array}$ & $\begin{array}{c}\text { Standard } \\
\text { deviation }\end{array}$ \\
\hline 1 & HDPE & 10 & 16 & 0.06 & 1.037 & 0.612 & 13 & HDPE & 8 & 16 & 0.05 & 0.678 & 0.183 \\
\hline 2 & HDPE & 10 & 32 & 0.03 & 2.078 & 0.559 & 14 & HDPE & 8 & 32 & 0.02 & 1.893 & 0.999 \\
\hline 3 & HDPE & 10 & 16 & 0.15 & 0.854 & 0.213 & 15 & HDPE & 8 & 16 & 0.12 & 0.583 & 0.138 \\
\hline 4 & HDPE & 10 & 32 & 0.07 & 1.160 & 0.369 & 16 & HDPE & 8 & 32 & 0.06 & 1.328 & 0.567 \\
\hline 5 & POM-C & 10 & 16 & 0.06 & 1.699 & 0.176 & 17 & POM-C & 8 & 16 & 0.05 & 0.743 & 0.169 \\
\hline 6 & POM-C & 10 & 32 & 0.03 & 1.449 & 0.531 & 18 & POM-C & 8 & 32 & 0.02 & 1.306 & 0.382 \\
\hline 7 & POM-C & 10 & 16 & 0.15 & 1.040 & 0.232 & 19 & POM-C & 8 & 16 & 0.12 & 0.457 & 0.131 \\
\hline 8 & POM-C & 10 & 32 & 0.07 & 1.172 & 0.351 & 20 & POM-C & 8 & 32 & 0.06 & 1.268 & 0.438 \\
\hline 9 & PA 6 & 10 & 16 & 0.06 & 4.375 & 1.313 & 21 & PA 6 & 8 & 16 & 0.05 & 2.992 & 0.870 \\
\hline 10 & PA 6 & 10 & 32 & 0.03 & 6.869 & 1.969 & 22 & PA 6 & 8 & 32 & 0.02 & 4.521 & 0.476 \\
\hline 11 & PA 6 & 10 & 16 & 0.15 & 3.259 & 0.529 & 23 & PA 6 & 8 & 16 & 0.12 & 2.669 & 0.603 \\
\hline 12 & PA 6 & 10 & 32 & 0.07 & 6.594 & 2.486 & 24 & PA 6 & 8 & 32 & 0.06 & 4.194 & 0.579 \\
\hline
\end{tabular}

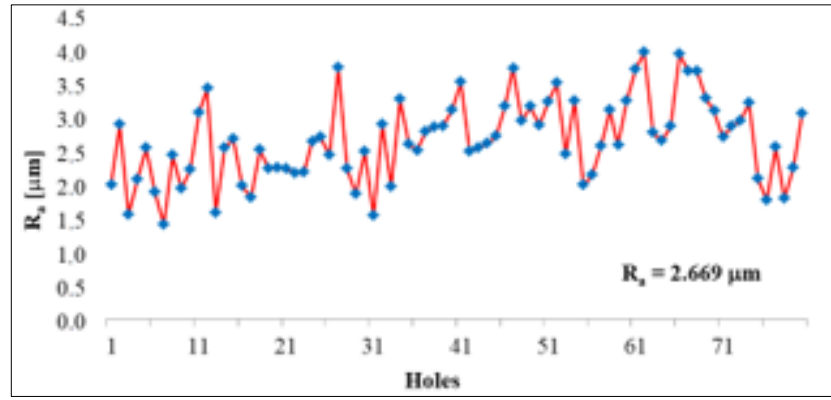

Figure 10. Variation of roughness $R_{a}[\mu \mathrm{m}]$ PA $6, D=8 \mathrm{~mm}, v=16 \mathrm{~m} / \mathrm{min}, F=0.05 \mathrm{~mm} / \mathrm{rev}$

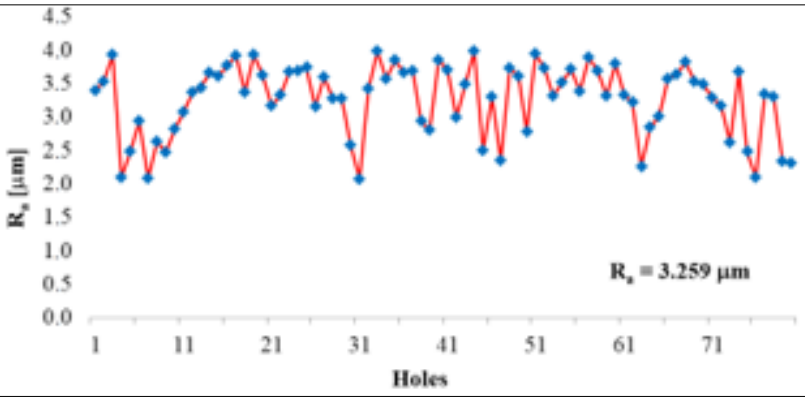

Figure 11. Variation of roughness $R_{a}[\mu \mathrm{m}]$ PA 6, $D=10 \mathrm{~mm}, v=16 \mathrm{~m} / \mathrm{min}, F=0.15 \mathrm{~mm} / \mathrm{rev}$

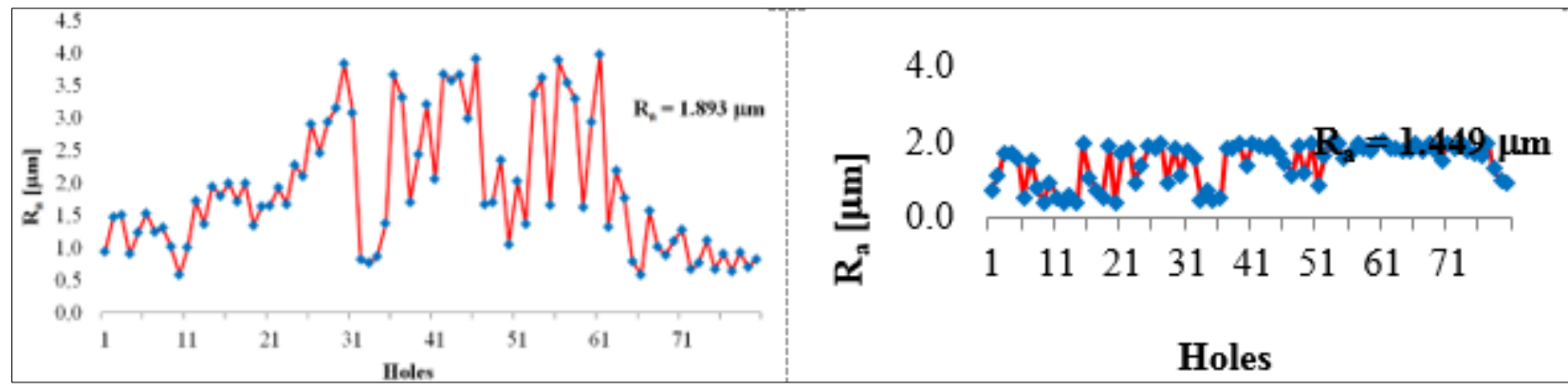

Figure 12. Variation of roughness $R_{a}[\mu \mathrm{m}]$ HDPE, $D=8 \mathrm{~mm}, v=32 \mathrm{~m} / \mathrm{min}, F=0.02 \mathrm{~mm} / \mathrm{rev}$

Figure 13. Variation of roughness $R_{a}[\mu \mathrm{m}]$ POM-C, $D=10 \mathrm{~mm}, v=32 \mathrm{~m} / \mathrm{min}, F=0.03 \mathrm{~mm} / \mathrm{rev}$ 
With the help of microstructural analyses performed by electron microscopy, using low vacuum Quanta 200 SEM equipment, with tungsten electron source, with three imaging modes (high vacuum, low vacuum and ESEM), it was possible to evaluate the state of the surface of the three materials obtained by drilling. Thus, Figure 14 shows the SEM image of some samples of polymeric materials POM-C, PA6, HDPE types - in cross-section through a hole machined with a twist drill $D=10 \mathrm{~mm}, v=16$ $\mathrm{m} / \mathrm{min}, F=0.15 \mathrm{~mm} / \mathrm{rev}$.

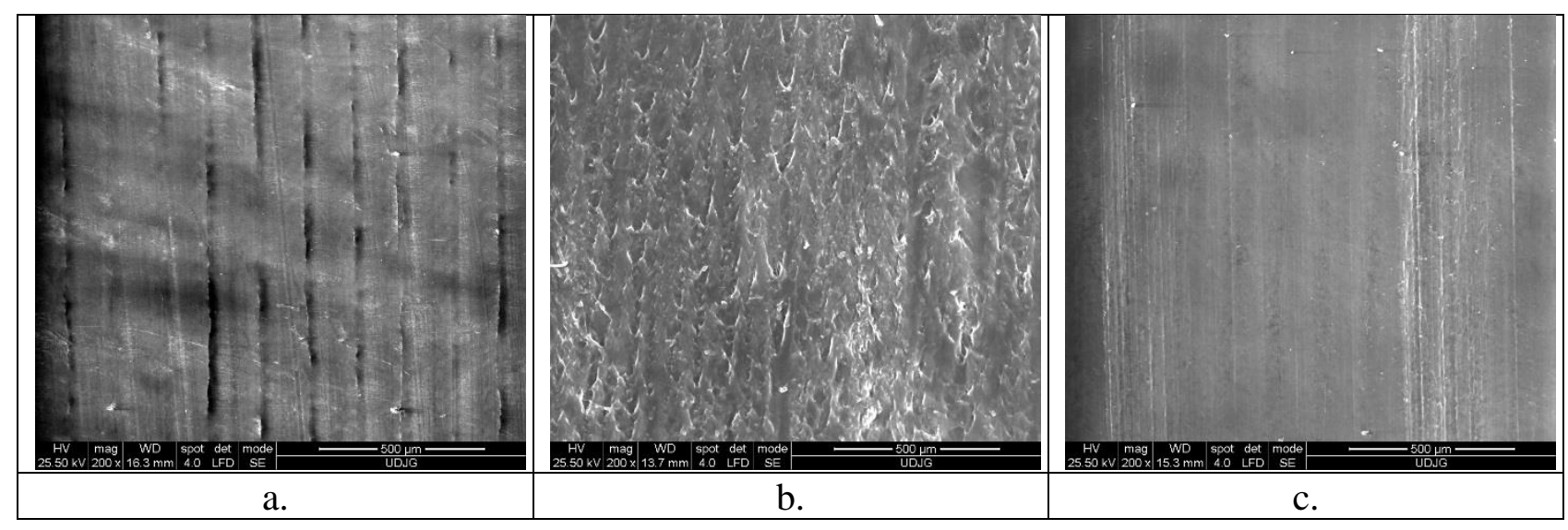

Figure 14. SEM images (cross-sectional view of the drilled hole) of the POM-C (a); PA6 (b) and HDPE (c) - $500 \mu \mathrm{m}$ scale bar

It can be noticed that, visually, on a $500 \mu \mathrm{m}$ scale, POM-C and HDPE materials have a better defined surface condition compared to PA 6, where exfoliation of material, with effect of plastic deformation on the generated surface, can be observed.

\section{ANN and the Prediction of Surface Roughness}

Neural networks are universal approximators, and they work best if the system they model has a high tolerance to error. The software was JustNN, version 4.0a, the target error was 0.0001 for all errors and the learning rate was 0.6. The learning process was stopped when all the errors were below 0.0001 .

The neural model consists of three layers.

The first layer is called the input layer. This layer contains 3 neurons that correspond to the input variables (drill diameter $-D$, cutting speed $-v$ and the feed rate $-F$ ).

The second layer, called the hidden layer, contains 4 hidden neurons. The number of hidden layers and the number of hidden neurons in this layer were determined by trial-and-error method.

The last layer is called the output layer and contains a neuron corresponding to the output variable (roughness of the processed surface $R_{a}$ ). Thus, for the multilayer neural networks used, for each of the three types of materials, neural networks with the following input parameters were learned and trained: drill diameter ( 8 and $10 \mathrm{~mm}$ respectively); cutting speed $(16$ and $32 \mathrm{~m} / \mathrm{min}$ ) and feed rate.

In this way, 8 possible combinations are obtained for each of the materials. In the training of the networks, 7 combinations were used, one of the 8 combinations being employed to verify the result of the training, Figure 15. This combination that was actually used to validate the neuronal model, was randomly selected by the program. 


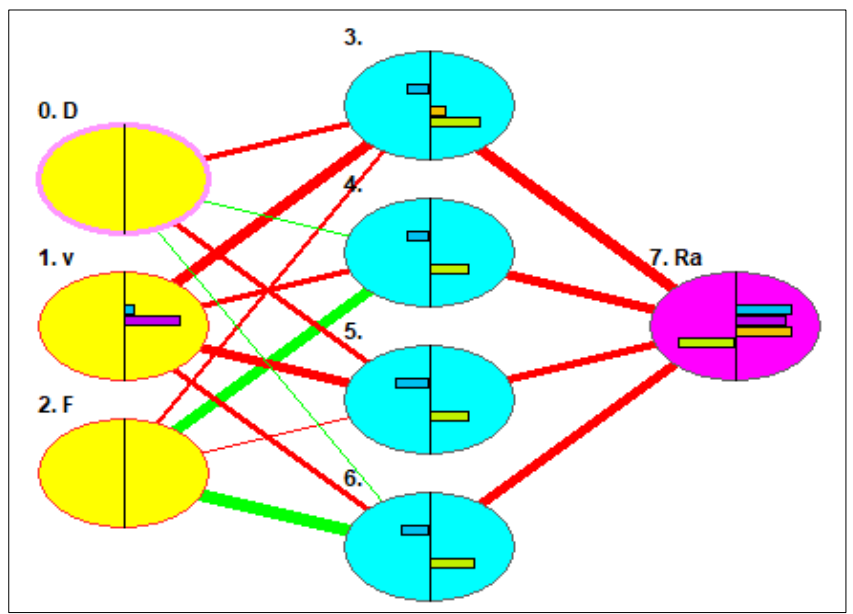

Figure 15. Neural model for roughness $R_{a}$ prediction

Following the query of the networks, we obtained roughness values that fall within the field of roughness measured for various combinations. As an example, there are 3 such combinations, Table 6: PA6 material, $D=10 \mathrm{~mm}, v=16 \mathrm{~m} / \mathrm{min} ; F=0.15 \mathrm{~mm} / \mathrm{rev}$; HDPE material, $D=8 \mathrm{~mm}, v=32 \mathrm{~m} / \mathrm{min} ; F=0.02$ $\mathrm{mm} / \mathrm{rev}$; POMC material, $D=10 \mathrm{~mm}, v=32 \mathrm{~m} / \mathrm{min} ; F=0.03 \mathrm{~mm} / \mathrm{rev}$.

Table 6. Results of ANN query for 3 combinations

\begin{tabular}{|l|c|c|c|c|c|}
\hline \multicolumn{1}{|c|}{ Combination } & $\begin{array}{c}R_{a} \min \\
{[\mu \mathrm{m}]}\end{array}$ & $\begin{array}{c}R_{a} \text { Expected } \\
{[\mu \mathrm{m}]}\end{array}$ & $\begin{array}{c}R_{a} \max \\
{[\mu \mathrm{m}]}\end{array}$ & $\begin{array}{c}R_{a} \text { average } \\
\text { value }[\mu \mathrm{m}]\end{array}$ & $\begin{array}{c}\text { Relative } \\
\text { error }[\%]\end{array}$ \\
\hline PA6, $D=10 \mathrm{~mm}, v=16 \mathrm{~m} / \mathrm{min} ; F=0.15 \mathrm{~mm} / \mathrm{rev}$ & 2.061 & 3.0115 & 3.979 & 3.259 & 7.59 \\
\hline HDPE, $D=8 \mathrm{~mm}, v=32 \mathrm{~m} / \mathrm{min} ; F=0.02 \mathrm{~mm} / \mathrm{rev}$ & 0.578 & 2.0676 & 3.963 & 1.893 & -9.22 \\
\hline POMC $, D=10 \mathrm{~mm}, v=32 \mathrm{~m} / \mathrm{min} ; F=0.03 \mathrm{~mm} / \mathrm{rev}$ & 0.369 & 1.4853 & 1.998 & 1.449 & -2.50 \\
\hline
\end{tabular}

In defining the average value of surface roughness $(\mathrm{Ra})$, the following parameters are important, in descending order: the cutting speed $(v)$, feed rate $(F)$, drill diameter $(D)$, Figure 16. In order to control the defining characteristic of the surface state of the polymeric materials processed by drilling, a statistical control of the process was made through a software application elaborated for this purpose and created in the Java programming language.

It analyses a database consisting of the measured roughness values and identifies whether these values have a normal distribution from a statistical point of view. The relative error is below $10 \%$ for any of machined materials.

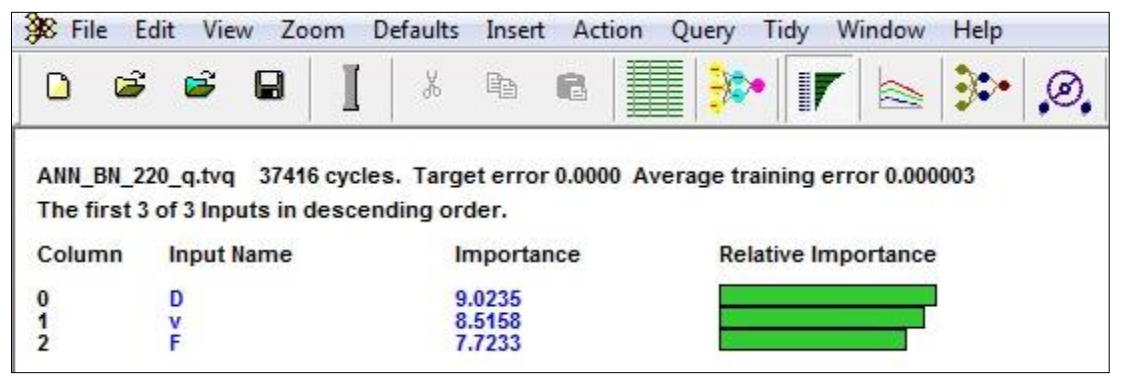

Figure 16. The importance of the input parameters in the ANN prediction for HDPE, $D=8 \mathrm{~mm}, v=32 \mathrm{~m} / \mathrm{min} F=0.02 \mathrm{~mm} / \mathrm{rev}$

Figure 17 presents the main statistical indicators calculated for the values of roughness $R_{a}$. These statistical indicators are displayed both numerically and graphically. 




a

$\mathrm{b}$

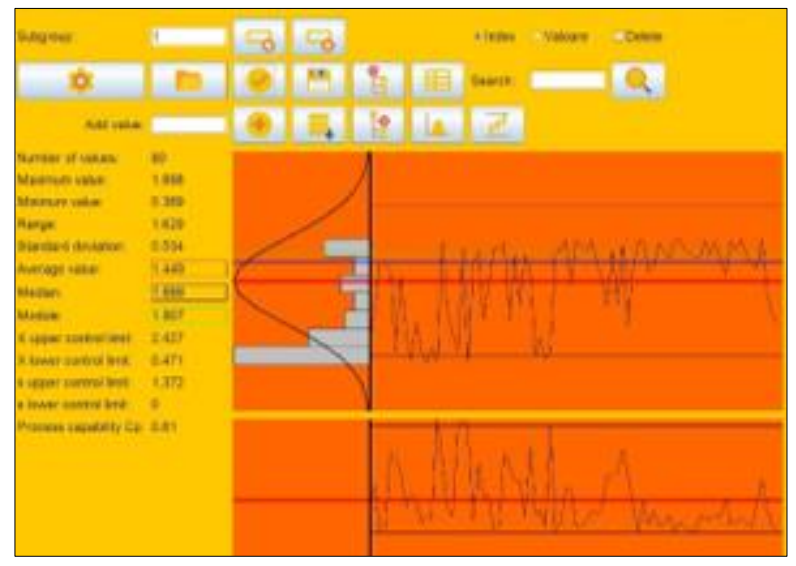

$\mathrm{c}$

Figure 17. Statistical control of the roughness measurement process $R_{a}$ : PA6, $D=10 \mathrm{~mm}$, $v=16 \mathrm{~m} / \mathrm{min} ; F=0.15 \mathrm{~mm} / \mathrm{rev}$ (a); HDPE, $D=8 \mathrm{~mm}, v=32 \mathrm{~m} / \mathrm{min} ; F=0.02 \mathrm{~mm} / \mathrm{rev}$ (b); POMC, $D=10 \mathrm{~mm}, v=32 \mathrm{~m} / \mathrm{min} ; F=0.03 \mathrm{~mm} / \mathrm{rev}$ (c)

In all the 3 cases subject to analysis, it can be observed that the value predicted through the artificial neural networks for roughness $R_{a}$ is within the limits defined by the value obtained from the measurements and the value specified by the statistical control software application. Thus, by using the software designed and programmed within the Department of Manufacturing Engineering, the Faculty of Engineering, "Dunărea de Jos" University of Galați, it is possible to follow the process and, in case a tendency to go out of control limits is noticed, to modify the process parameters that caused the change in quality characteristics.

\section{Conclusions}

The experiments conducted for the 24 plates of PA6, POM-C and HDPE 1000, with 2 drills of different diameters $(\varnothing 8$ and $\varnothing 10 \mathrm{~mm})$, with the same feed rates and cutting speed, allowed us to highlight the following conclusions:

- the diameter of the drill is a significant factor for roughness, for the drill dimensions used in the experiment; in other words, the larger the diameter of the drill, the higher the value of roughness of the machined surfaces. This can be highlighted both in terms of the simplified geometric model, theoretically, and from the determinations made.

- the geometrical model of the roughness, without rigorous determination of the generated roughness, indicates the main geometric parameters of the drill and the cutting regime that influence the roughness. In this way, it can be determined whether a certain combination of the geometric shape of the drill and the parameters of the cutting regime is more favourable in terms of the roughness obtained. 
- the extremely small differences between the geometric roughness values obtained by the geometrical prediction model are obviously attributed only to the differences in diameter and helical parameters, without the influence of the material to be processed;

- for the simplified geometric model, the roughness expressed by constructive parameters $(D-$ drill diameter; $p$ - helical parameter; $\kappa$ - main point angle), note should be taken that angle $\kappa$ is $60^{\circ}$. It is obvious that a geometry with a smaller point angle, between $45^{\circ}$ and $22^{\circ}$, also leads to a reduction of the transverse roughness, so the geometry of the cutting tool is also an essential factor that influences the state of the processed surface. Experimental machining were done using only helical drills with working angle $\kappa=60^{\circ}$.

- from the three polymeric materials experimentally processed the best value of roughness is that of the POM-C material, in relation to the mechanical characteristics and from the observations during processing on how chips detach;

- as regards cutting speed variation, it was noticed that the value of roughness decreases, for each material separately, as the value of the feed rate increases;

- however, the differences existing in the geometrical prediction model and the values recorded experimentally can also be put on account of the fact that the geometric model does not take into consideration the effects due to the cutting speed nor the material to be processed.

The paper highlights that the predicted values of the neural network are close to the average values of the measurements and are between the minimum and maximum values determined experimentally. Therefore, the results obtained by iterating the neural network, with data from the training domain, can serve for a reliable prediction of the roughness obtained by processing.

Acknowledgments: This work was supported by a grant of the Romanian National Authority for Scientific Research and Innovation, CNCS-UEFISCDI, project number PN-III-P1-1.2-PCCDI-20170446-TFI PMAIAA, within PNCDI III.

\section{References}

1. GAITONDE, V.N., KARNIK, S.R., CAMPOS RUBIO, J.C., DE OLIVEIRA LEITE, W., DAVIM, J.P., Journal of Composite Materials, 48(1), 2014, p. 21.

2. VASILE, G., FETECĂU, C., ȘERBAN, A., Mater. Plast., 51(2), 2014, 205.

3. KURAM, E., Composites Part B, 88, 2016, p. 85.

4. LOKESH, K.S., PINTO, T., RAMACHANDRA, C.G., Int. J. of Eng. and Information Systems, 1(5), 2017, p. 71.

5. CAGGIANO, A., IMPROTA, I., NELE, L., Materials, 11(8), 2018, p. 1470.

6. KUMAR, D., SINGH, K.K., ZITOUNE, R., Advanced Manufacturing: Polymer \& Composites Science, 2016, DOI: $10.1080 / 20550340.2016 .1187434$.

7. *** SC SIDEM ROMANIA, http://www.sidem.be/.

8. *** Grup Renault România, http://www.renault-technologie-roumanie.com/.

9. DOMINGO, R., MARÍN, M., DE AGUSTINA, B., CALVO, R., Procedia Engineering, 132, 2015, p. 448.

10. GAITONDE, V.N., KARNIK, S.R., CAMPOS R.J., ABRAO, A.M., ESTEVES C.A., DAVIM, J.P., Journal of Composite Materials, 46(21), 2011, p. 2659.

11. BAROIU N., TEODOR V.G., BERBINSCHI S., SUSAC, F. OANCEA, N., Indian Journal of Engineering and Materials Sciences, 23(5), 2016, p. 237.

12. JAGTAP, K.A., KULKARNI, S.A., SANGWIKAR, A.S., IOSR J. of Mechan. \& Civil Engineering, 2016, p. 42.

13. BAROIU N, BERBINSCHI S, TEODOR V.G., SUSAC F, OANCEA N, IOP Conference Series-Materials Science and Engineering, 227, 2017, UNSP 012013.

14. BENARDOS, P.G., VOSNIAKOS, G.C., Int. J. Mach. Tools. Manuf., 43, 2003, p. 833.

15. KURT, M., BAGCI, E., KAYNAK, Y., Int. J. Adv. Manuf. Technol., 40, 2009, p. 458.

16. RAJA, R., SABITHA, J., International Journal of Mechanical and Production Engineering Research and Development (IJMPERD), 7(6), 2017, p. 351. 
17.CHANDRASEKARAN, M., DEVARASIDDAPPA, D., Advances in Production Engineering \& Management, 9(2), 2014, p. 59.

18. VRABEL, M., MANKOVA, I., BENO, J., TUHARSKÝ, J., Procedia Engineering 48, 2012, p. 693.

19. UYSAL, A., ALTAN, E., ACTA PHYSICA POLONICA A, 129(4), 2016, p. 442.

20. TSAO, C.C., HOCHENG, H., J. of Mat. Processing Techn., 203, 2008, p. 342.

21. AYKUT, S., Acta Polytechnica Hungarica, 8(2), 2011, p. 21.

22. SANJAY, C., JYOTHI C., Int. J. Adv. Manuf. Technol., 29, 2006, p. 846.

23. SUSAC, F., TABACARU, V., TEODOR, V.G., BAROIU, N., Mater. Plast., 56(1), 2019, 245.

24. BAROIU, N., ILIUŢĂ, V., RÎPĂ, M., The Annals of "Dunărea de Jos" University of Galati, Fascicle V, II, 2012, p. 39.

25. *** EN ISO 4287-1997 - Geometrical Product Specifications (GPS) - surface texture: profile method - terms, definitions and surface texture parameters.

26. *** Mitsubishi Chemical Advanced Materials - Thermoplastics, https://www.mcam.com.

Manuscript received: 11.10 .2019 